\title{
Internal And External Attributions As Determinants Of Athletes` High Performance In Individual And Team Sports In Selected Tertiary Institutions, Southwest, Nigeria
}

\author{
Emmanuel Okwong Okon \\ Wesley University, Nigeria
}

\begin{abstract}
The study was designed to investigate relationship of internal and external attributions on high performance in individual and team sports in tertiary institutions athletes to redress low performance of athletes. To achieve the purpose of the study, student athletes of tertiary institutions in southwest states, Nigeria, who had participated in inter-colligate sports competitions were examined, These four hundred and sixty-three athletes made up of 206 in individual and 257 in team sports were selected as participants. Multi-stage sampling technique was used to select states through convenience sampling technique, institutions through simple random sampling technique, sports through purposive sampling technique, and high performer athletes were determined by their position ranking of $1^{\text {st }}-3^{\text {rd }}$ secured during sport competitions. The instruments designed to measure internal and external attributions responses of the respondents was Rotter's I-E developed by Rotter (1966). The statistical analysis of Pearson`s Product Moment Correlation, Regression were used to test the relationship at significance level of 0.05 levels. The finding of the study showed that each internal and external attributions revealed no significant relationship to high performance. Rather, coaches and athletes need to be informed, the consequent effect of attributions to either high or low performance before, during and after sport competitions
\end{abstract}

Keywords: Internal and External Attributions, Performance, Individual and Team Sports, Tertiary Institutions.

\section{INTRODUCTION}

Sports is a multi-faceted entity, usually organized into competitions based on type of sports the athletes engages in, and described as individual sports(organized singly e.g. Athletics) and team sports(organized in group e.g. soccer). Invariably, both sports athletes or players post some innate personal and situational variables that may influence their performance. Gillet \& Rosner (2008) opined that individual sports athletes are bound to experience greater feelings of autonomy than their team based counterparts, possibly due to greater freedom to make decisions. Furthermore, apart from lower intrinsic motivation, there are lot of challenges faced by members of team sports as result of the need for a greater level of coordination in such unstable environments where sports events take place. Also, accuracy in the ability to gauge the thought of another person among coaches of individual sport is higher than in team sports (Lorimer \& Jowett 2009). Regardless of specific variables noted in each sports, performance at the state of psychological flow, which is the optimal state in which an individual's ability matches the challenge of an activity which involve complete absorption and focus, there is a positive relationship between athlete`s experience of psychological flow and optimal performance. Alycia (2015) reported that the flow is universal among athletes regardless of what sport athletes or players played or the type of sports in which they are involved. The often neglect of these personal and situational variables inherent in both sports athletes and 
players to more preference for physical training or focus in achieving performance may often sees the athletes or players not achieving optimal performance or drop out totally.

In an organized sports competitions, tertiary institutions played greater role of being an avenue of getting national athletes through their various sports bodies, sports curriculum and sports competitions stage biannually; most importantly enhancing ways of promoting good performance. However, considering the effort of these tertiary institutions to produce athletes for national or international engagements, tertiary institutions athletes in Nigeria are no where to be found during selection of athletes and players for national and international engagements. A lot had been said in this regard of getting our athletes and players from grassroots (tertiary institutions inclusive) by all sports lovers, yet, no sign of single athletes nor players from this sector. Perhaps, it is the views that their performance is not up to what is required as often reported by media(Osun defender 2018). Good performance is a prime focus of all sports stakeholders to the extent that means of enhancing it becomes prime focus also. "Sports performance is associated with aesthetic satisfaction; that is, it is appreciated as form of beauty" (Matt 2006). Accordingly, each athlete participating in sports competition hold selfperception, social comparision and self attribution in high esteem to show how they feel and making self evaluation about their performance (Ohtskuka 2000). Performance appraisal could be internally and externally defined or attributed through individual experiences in any task involved (Ohtskuka 2000). The internal and external appraisal and definition of performance by athletes is what sports psychologist termed Attribution. An individual can determine how and what conditions the personal(internal) attribution or situational(external) behaviour of his/her and others has been successful (Sodabeh 2013).

An internal and external attributions stem from the writing of Rotter (1966),which other researchers build upon like Wiener(1972,1974) to proposed Attributional theory of achievement motivation and emotion characterized by locus of causality made of internal and external, stability made of stable and unstable to which an individual ascribed causes of their performance (Farrha 2004); when an individual attribute internally, he/she perceived performance as his/her own effort while when externally attributed, he/she believes that their performance was due to external forces or powerful others(Farrha 2004). Generally, when there is success or high performance, there is tendency to internalize it, while failure or low performance occurred, there is tendency to externalize it or vice-versa. However, it is believe that this assertion is not always supported in sports setting, because observation of attributions made by individual or athletes from previous researchers showed that while some claimed no effect on performance, some hold that successful athletes made more internal, stable and controllable attribution than unsuccessful athlete (Ohtskuka 2000). When perception and reality are examined in an outcome, the pattern of attributing in research conducted so far on athletes indicating external attribution for failure and internal attribution for success may not hold if possibility is to maintain self-esteem in a "self-serving" or "hedonic" bias nature is there. For it is opined that attribution is not fixed or determined; it is a piece of who you are and what you wish to be (Nick 2015).

Highlighting attributions as contributory factor in performance in this regard, Hanrahan, Cerin and Hartel (2003) reported that attributions to successful or winning outcome would bring about continuity in future in similar performance rather than when attributions is unsuccessful or failure outcome. In likewise, attribution to internal, stable, personally, controllable, external, unstable, uncontrollable would exhibit a higher level of both self-rated and coach-rated performance than athlete that shows otherwise. 
The need to redress athletes` and players` performance in light of substantive claims that athletes' and players' attributions played a major contributing factor in experiencing high performance become necessary. This would provide more information on attributions as determinant of a specific performance without self-serving bias to enhance the generalization of attribution theory and process.

The main purpose of this study is to examine internal and external attributions as determinant of athletes` performance in individual and team sports in tertiary institutions in southwest, Nigeria. Specifically, the study intends to: ascertain relationship between internal attribution and high performance; and investigate relationship between external attribution and high performance in individual and team sports.

It was hypothesized that there will be no significant relationship between internal attribution and high performance in each of individual and team sports; and there will be no significant relationship between external attribution and high performance in each of individual and team sports

\section{MATERIAL AND METHODS}

The purpose of the study was achieved with 463 athletes drawn from tertiary institutions in southwest, Nigeria were randomly selected as respondents. The 463 respondents comprises of 206 individual and 257 team sports. The instruments used to measure the internal and external attributions responses of respondents were the Locus of Control Scale (Rotter 1966). Multi-stage procedure were used to obtained a wide spread of the respondents: First stage was selection of three States using convenience sampling technique, selection of twelve institutions using simple random sampling technique and selection of sports in each institution using purposive sampling technique. The questionnaires were personally administered to the respondents who were identified through the help of their various coaches, who equally render assistant for the study. All respondents voluntarily agreed to participate and were adequately available to answer the questions and turn in the questionnaire appropriately. The questionnaires collected were scored per instruction and raw data were quantified and statistically processed. Statistical analysis of mean, standard deviation, Pearson`s Product Moment Correlation and regression were used to test the degree of relationship of internal and external attributions factors and sports performance at significance value of 0.05

\section{RESULTS}

The result of the statistical analysis are hereby presented in Tables

Table 1

Correlation between internal attribution and high performance on each of Individual and Team sports.

\begin{tabular}{lllll}
\hline Attributions & Sports & $\mathrm{N}$ & " $\mathrm{r}$ " & sig \\
\hline Internal & Overall & 463 & 0.035 & 0.449 \\
Attribution & Individual & 206 & 0.037 & 0.594 \\
& Team & 257 & 0.034 & 0.588 \\
\hline
\end{tabular}

As shown on the table above, individual sports athletes did not differ significantly from their team sports athletes in the attribution of high performance to internal factor. Also, in 
examining them together, no significant relationship was noted attributing high performance to internal factor as the " $r$ " value indicated higher significant level greater than 0.05 in each individual and team sports. Regression analysis done as highlighted below in table 2 showed similar result for both sports. This result accepted the null hypothesis as it was set.

Table 2

Regression Analysis of the impact of internal attribution on high performance in each of the Individual and Team sports.

\begin{tabular}{lllll}
\hline Attributions & Sports & $\mathrm{N}$ & “ $\mathrm{r}$ ( & sig \\
\hline Internal & Overall & 463 & 0.757 & 0.449 \\
Attribution & Individual & 206 & 0.534 & 0.594 \\
& Team & 257 & 0.543 & 0.588 \\
\hline
\end{tabular}

Table 3

Correlation between external attribution and high performance in each of Individual and Team sports.

\begin{tabular}{llccc}
\hline Attributions & Sports & $\mathrm{N}$ & "r" & sig \\
\hline External & Overall & 463 & -0.058 & 0.214 \\
Attribution & Individual & 206 & -0.080 & 0.256 \\
& Team & 257 & -0.037 & 0.554 \\
\hline
\end{tabular}

As shown on the table above, individual sports athletes did not differ significantly from their team sport athletes in the attribution of high performance to external factor. Also, in examining them together, no significant relationship was noted attributing high performance to external factor as the " $r$ " value indicated higher significant level greater than 0.05 in each individual and team sports. Regression analysis done as highlighted below in table 4 showed similar results for both sports. This result accepted the null hypothesis as it was set.

Table 4

Regression Analysis of the impact of external attribution on high performance in each of the Individual and Team sports.

\begin{tabular}{llccc}
\hline Attributions & Sports & $\mathrm{N}$ & "r" & sig \\
\hline External & Overall & 463 & -1.243 & 0.214 \\
Attribution & Individual & 206 & -1.140 & 0.256 \\
& Team & 257 & -0.593 & 0.554 \\
\hline
\end{tabular}

\section{DISCUSSION}

From the result of this study, individual sport showed insignificant relationship to high performance on internal/external attributions, similarly, team sport showed insignificant relationship to high performance on internal/external attributions. Further statistical analysis 
of regression revealed that attributions to causality showed insignificant predictive values in each sports. It is opined that in self-serving bias explanation, this may perhaps not considered, but to believe that attributions is not fixed, but a pieces of what you are(Nick 2015) gives possible explanation as finding reveals. Moreso, performance outcome is byproduct of many personal attributes contributing to whether athletes or players succeed or fail ( ). This disagreed that winner/successful tends to made more internal, stable and personal controllable attributions than losers/unsuccessful athletes ( Hamilton \& Jordan 2000), while it agreed with finding that competitors attributed their outcomes to internal attribution factors regardless of whether winning or losing outcome or performance occurred ( Rebeka et. al 2017).

\section{CONCLUSION}

The study concluded that internal and external attributions have no influence in determining high performance. This finding has implication for coaches and other sports stakeholders in the areas of achievement motivation and goal setting techniques.

\section{References}

Alycia, P. (2014, May 10) The Psychology of Individual and Team Sports(Basic). University of Utah. Retrieved from Sportscience.utah.edu/team-Psychology-Basic.

Farrha, A. (2004) STUDY OF ATTRIBUTIONS OF LOW ACHIEVERS AND HIGH ACHIEVERS ABOUT THE PERCEIVED CAUSES OF THEIR SUCCESS AND FAILURE.

Published Thesis of University of Arid Agriculture Rawalpindi, Pakistan.

Gillet, N., \& Rosnet, E. (2008) Basic need satisfaction and motivation in sport.

Journal of Sport Psychology, 10

Hamilton, P. R. \& Jordan, J. S. (2000) Most successful and Least successful performance: Perception of causal attribution in high school Track Athletes.

Journal of Sport Behaviour 23, 3, 245-254

Hanrahan, S. J., Cerin, E.., \& Hartel, C. (2003) Achievement goal orientation, Attributional style and motivational climate as predictor of performance and persistence. Paper presented at the Association for the advancement of Applied sport psychology annual conference, Philadelphia

Lorimer, R., \& Jowett, S., (2009) Empathic accuracy in coach-athlete dyads who participate in Team and Individual Sports. Psychology of Sport and Exercise. 10: 152-158

Matt, J. (2006) Sport Psychology: A student’s Handbook Routledge, New York, NY 10016 USA

Nick, I. (2015, April 5) How your “Attributional Style” determines your effectiveness at work.

Retrieved from http://www.dearthink.com

Ohtskuka, K., \& Hyam, P. (2003) Internal and External attributions of success and failure in gambling and nongambling situation. In G. Coman, M. Walker, A. Jackson. \& P. Thomas (Eds). The proceedings of the $12^{\text {th }}$ Annual National Association for Gambling Studies Conference, Melbourne. (Pp. 357-369).

Rebeka, P., Renata, B., \& Martina, J. (2017) WHY? A question behind every outcome finally answered. University of Zagreb, Croatia. Retrieved from http://bib.irb.hr/.../876569

Rotter, J. B.(1966) Generalized expectancies for internal versus external control of reinforcement. Psychological Monographs, 80 (1)

Sodabeh, M. (2013) A Review on the Attributions Theory in the Social Psychology

IOSR Journal of Humanity and Social Sciences, 8, 6, 74-76

Wiener, B. (2000) Intrapersonal and interpersonal theories of motivation from an attribution perspective.

Educational Psychology Review, 12, 1-14 